\title{
Multifunctional Bone Scaffolds: From Regeneration to Bone Cancer Therapy
}

\author{
Firoozeh Foroughi ${ }^{\# 1}$, Ashkan Bigham ${ }^{\# 2}$, Erfan Rezvani Ghomi ${ }^{3}$, Mohammad Rafienia ${ }^{4}$, Hongrong \\ Luo $^{5^{*}}$, Fatemeh Khosravi ${ }^{3}$ and Seeram Ramakrishna ${ }^{3 *}$ \\ ${ }^{1}$ Department of Materials Science and Engineering, Faculty of Engineering, National University of Singapore, Singapore
}

${ }^{2}$ Department of Biomaterials, Tissue Engineering and Nanotechnology, School of Advanced Technologies in Medicine (ATiM), Isfahan University of Medical Sciences, Iran

${ }^{3}$ Department of Mechanical Engineering, Center for Nanofibers and Nanotechnology, National University of Singapore, Singapore

${ }^{4}$ Biosensor Research Center, Isfahan University of Medical Sciences, Iran

${ }^{5}$ National Engineering Research Center for Biomaterials, Sichuan University, China

${ }^{\#}$ These authors contributed equally to this work

*Corresponding author: Seeram Ramakrishna, Department of Mechanical Engineering, Center for Nanofibers and Nanotechnology, National University of Singapore, Singapore 119260, Singapore

Hongrong Luo, National Engineering Research Center for Biomaterials, Sichuan University, China

\begin{tabular}{lll}
\hline ARTICLE INFO & Abstract \\
\cline { 1 - 2 } $\begin{array}{l}\text { Received: May 15, } 2020 \\
\text { Published: May 26, } 2020\end{array}$ & $\begin{array}{l}\text { Under the umbrella of bone scaffolds, there is a category called multifunctional } \\
\text { scaffolds capable of addressing different bone-related issues-bone cancer and } \\
\text { regeneration, simultaneously. Up to now, some techniques are being applied in clinics to } \\
\text { deal with bone tumors. However, filling up a critical size bone defect caused by a tumor } \\
\text { with a biomaterial to not only regenerate the defect, but also preventing recurrence } \\
\text { Citation: Firoozeh F, Ashkan B, Erfan Rez- } \\
\text { vani G, Mohammad R, Hongrong Luo, Seer- } \\
\begin{array}{ll}\text { am R, et al., Multifunctional Bone Scaffolds: } \\
\text { From Regeneration to Bone Cancer Ther- }\end{array}\end{array} \quad \begin{array}{l}\text { multifunctional scaffolds endowed with regeneration ability and more up-to-dated } \\
\text { bone cancer therapies-hyperthermia, photothermal, and localized drug delivery. }\end{array}$
\end{tabular}

From Regeneration to Bone Cancer Therapy. Biomed J Sci \& Tech Res 27(5)-2020. BJSTR. MS.ID.004572.

\section{Introduction}

A 3D bone scaffold is perceived as a biodegradable porous structure by which the healing process would be significantly accelerated [1]. An ideal bone scaffold is expected to have some basic properties as a porous material, which is

a. Biocompatible with suitable surface functional groups for cell adhesion and proliferation,

b. Biodegradable in a desirable rate close to tissue growth,

c. Highly porous with interconnected structure to support the transport of nutrients and waste removal, and finally,

d. Mechanically strong based on the application [2-4]. There are other scaffolds called multifunctional capable of addressing other issues like osteomyelitis, inflammation, and bone tumors besides possessing the basic requirements [5-8].

Despite of great advancements in recent years, cancer is still regarded as the second general cause of death [9]. Osteosarcoma (bone cancer) is notorious to choose its victims mostly through youth rather than mature $[10,11]$. Yet applying an effective solution to deal with malignant bone tumors is demanded due to incapability of either surgical intervention or radiotherapy to eradicate multifocal lesions entirely [12]. Moreover, systemic administration of chemotherapeutic drugs in the case of bone cancer has serious side-effects for liver and kidneys $[6,13,14]$. It is important to take into consideration an issue which is poor diffusion of chemical 
drugs molecules through bone tissue compared to a soft tissue and hence, a much higher drug's dosage is required resulting in irreparable effects on different organs of body [15].

Fortunately, newer therapies like hyperthermia, photothermal therapy, and localized drug delivery under the umbrella of tissue engineering and regenerative medicine (TERM) have opened alternative therapies to the traditional treatments [1618]. This question may be brought up that how TERM can push the boundaries of osteosarcoma treatment ahead. The answer is when a bone tumor is removed; it leaves behind a critical size defect, which cannot be healed spontaneously [19]. Therefore, TERM offers a multifunctional bone substitution capable of regenerating the defect beside eradication of remained cancerous cells on the defects wall. Regarding to enormous progress and rapid development in the bone tissue engineering recently, different multifunctional bone scaffolds are designed and developed; these scaffolds can address two critical issues, which are eradication of remained cancerous cells after surgery and restoring the bone defect simultaneously. The present review aims at introducing effective approaches toward bone cancer therapy and regeneration.

\section{Hyperthermia-Based Therapy}

Applying magnetism yielded multifunctional magnetic 3D scaffolds which are responsive to an external magnetic field (EMF) to address issues like treatment of bone tumors through hyperthermiabased therapy [20,21]. Hyperthermia-based bone cancer therapy is attracting more attention because of its efficiency to eradicate bone cancerous cells locally and decreasing catastrophic side effects of the other therapies such as radiotherapy (radiation) and non-targeted (systemic) chemotherapy (high dosages of chemotherapeutic drugs) [22]. Nonetheless, multifunctional magnetic 3D scaffolds are reported to have beneficial effects on bone tissue regeneration through stimulating osteoblast cells to be proliferated faster [23]. Shuai, et al. [24] fabricated a superparamagnetic-based scaffold to assess whether EMF has any stimulatory effect on the human umbilical cord-derived mesenchymal stem cells; through both in vitro and in vivo tests, it turned out that bone mineral density and new area bone fraction have been significantly increased in the exposure of EMF. Through hyperthermia therapy and in the exposure of EMF, a magnetic scaffold releases heat in the range of 41-46 ${ }^{\circ} \mathrm{C}$ based on the intended application [25].

Below the temperature of $41^{\circ} \mathrm{C}$, there is no effect on the cancerous cells and pointless to be assessed here, but any temperature that falls into the mentioned range $\left(41-46^{\circ} \mathrm{C}\right)$ is of a great significance from cancer therapy viewpoint. It is noteworthy that there is another category adopting temperatures above 46 ${ }^{\circ} \mathrm{C}$ (thermo ablation) and this one is reported to affect healthy tissues in a negative way beside cancerous tissues. The range between $42-46{ }^{\circ} \mathrm{C}$, which has attracted lots of attention, is called moderate hyperthermia and it is able to eradicate bone cancerous cells without adversely affecting healthy tissues [26,27]. It should be mentioned that by synthesis and designing a magnetic-based material in the bone scaffold's structure, hyperthermia therapy can be achieved. It is noteworthy that the magnetization saturation of scaffold, frequency, and magnitude of applied external magnetic field are governing factors by which the internal released heat can be precisely controlled [28]. Figure 1 shows the effects of EMF on osteogenicity and tumor therapy of magnetic scaffolds [29].

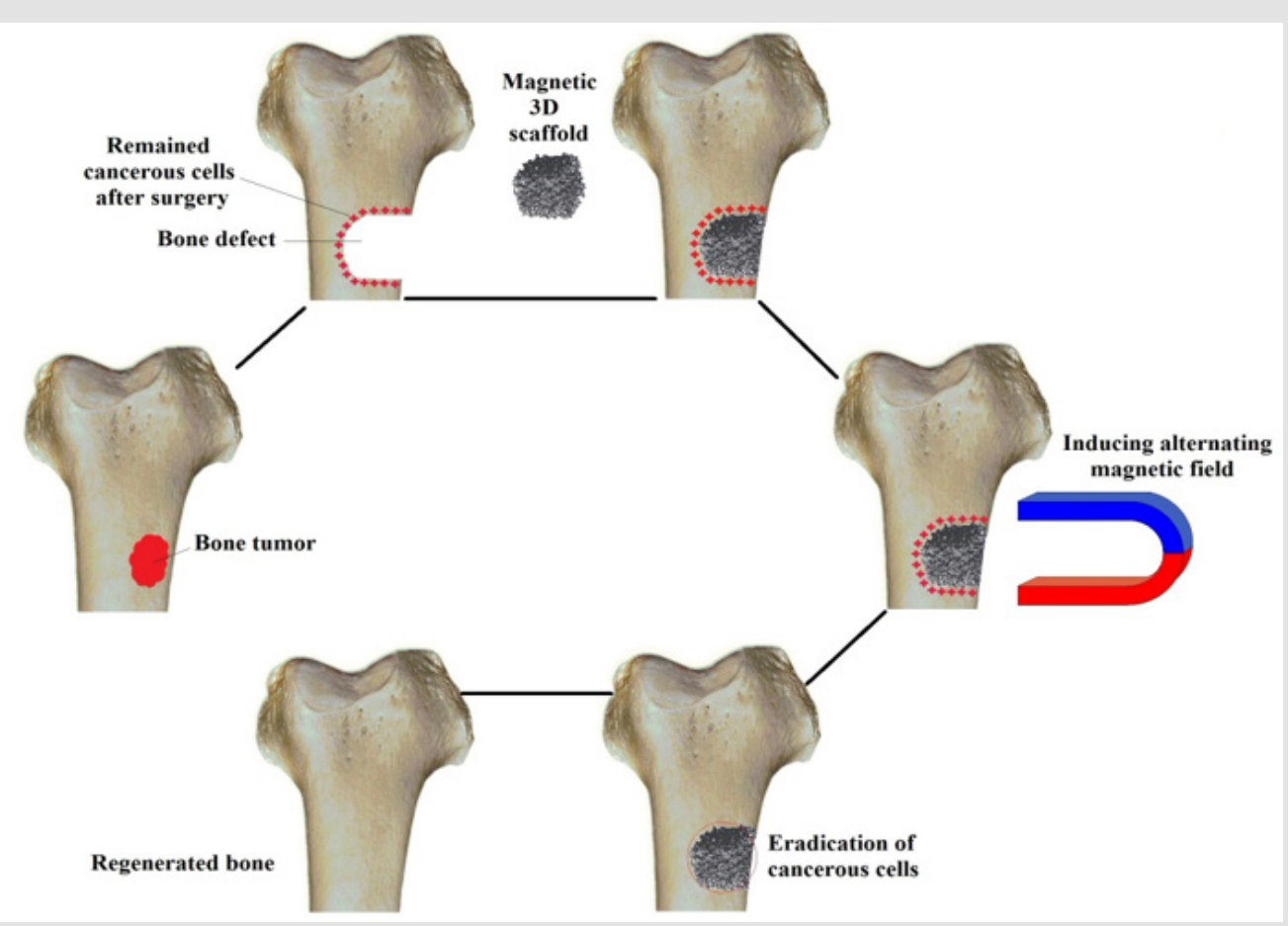

Figure 1: A schematic picture showing the effects of external magnetic field on a bone tumor [29]. 


\section{Photothermal-Based Therapy}

Another approach to kill bone cancerous cells is photothermal therapy which is reputable to be non-invasive and effective [30]. This therapy is based on designing bone scaffolds containing photothermal agents-grapheme oxide, transition metals, $\mathrm{MoS}_{2}$, carbon, $\mathrm{LaB}_{6}, \mathrm{CuFeSe}_{2}$, etc. [18,30-34]. It is well-known that these photothermal agents have catalytic capability to absorb near Infrared laser (NIR) followed by converting it to heat leading to the death of cancerous cells (Figure 2). Fu, et al. [32] developed a multifunctional bone scaffold composed of Larnite/carbon for simultaneous bone cancer therapy and regeneration; based on the obtained results, the scaffold effectively killed the cancerous cells in vitro and in vivo and the bone regeneration of Larnite/carbon was better than pure Larnite. On the upside, this method requires less high-tech instruments to excite the photo-thermal agents of bone scaffold (easy processing) and also by just addition of a single element through the structure of scaffold this kind of therapy would be available (cost-effective). On the downside, the efficiency of infrared diffusion to excite the photothermal element based on the depth of bone defect is vague and applying more powerful substitutions like ultraviolet is synchronized with other serious problems.

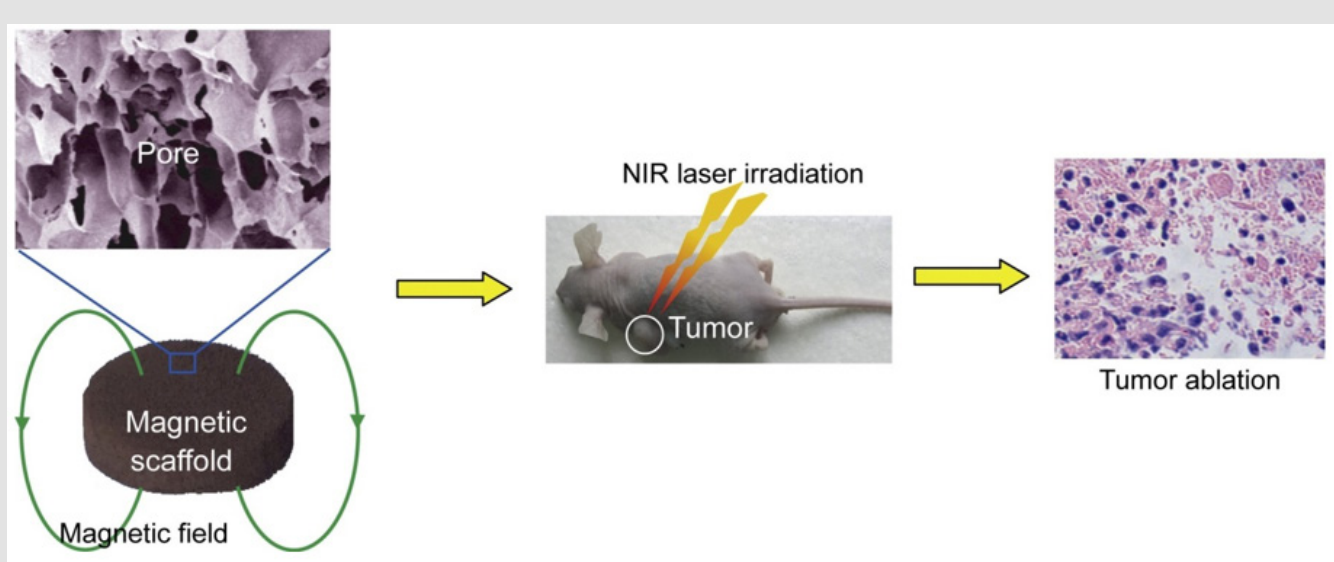

Figure 2: The effect of photothermal therapy on tumor ablation [11].

\section{Localized Drug Delivery}

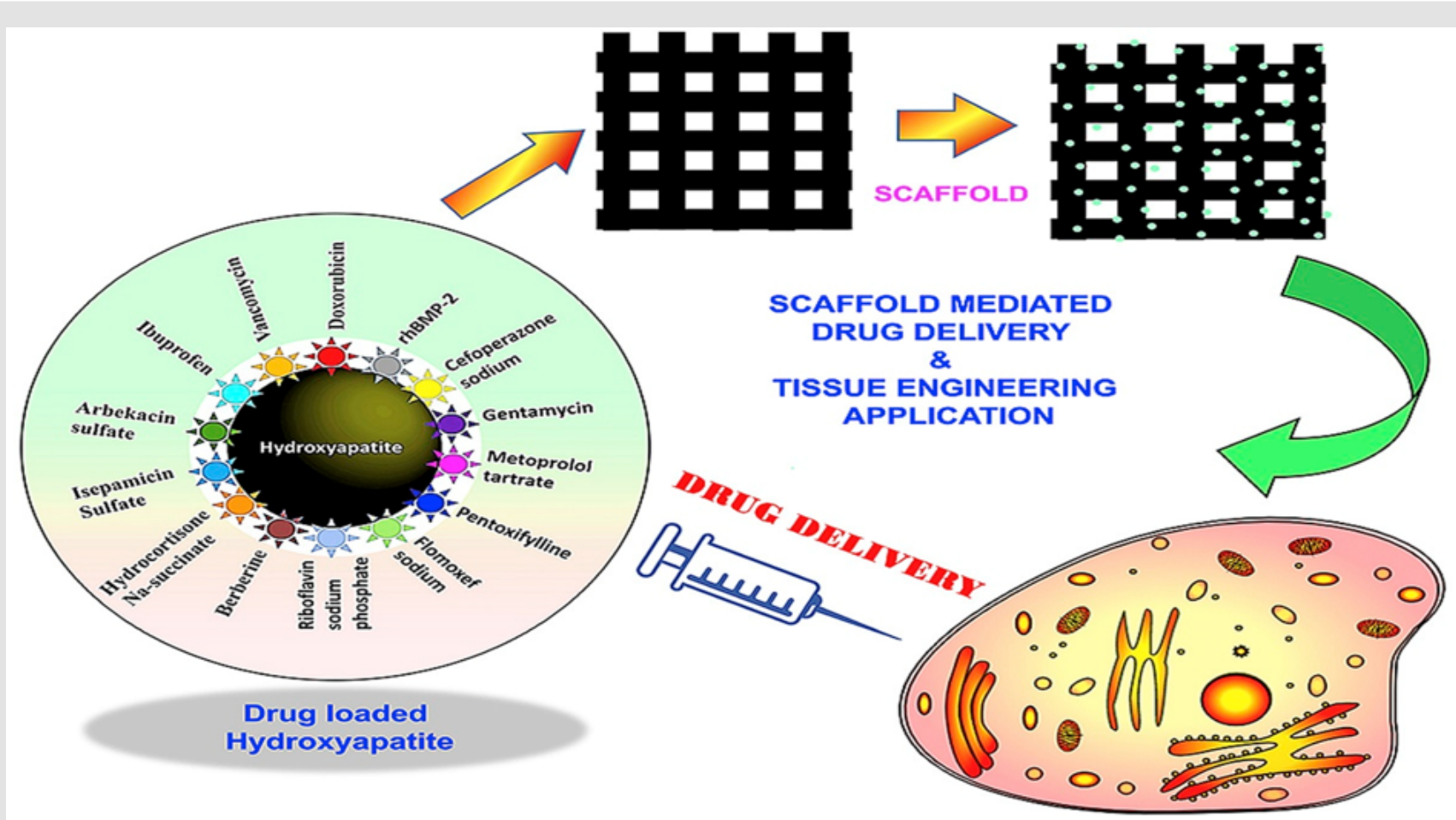

Figure 3: An illustration of different drugs loading on a hydroxyapatite bone scaffold and subsequent localized release of them in the bone defect [42]. 
Various ways are available for administration of drugs, which generally can be categorized as systemic and localized drug delivery $[35,36]$. Through the systemic way, a drug is injected through blood stream and then it will be distributed all over the body resulting in poor penetration of drug molecules into targeted tissue and also subsequent disadvantages for renal and liver [13,37]. This way is even more complicated for bone tissue due to poor blood stream through this tissue requiring higher dosages of the drug. Considering that in the case of bone cancer, the chemotherapeutic drugs should be administered and to reach the desired amounts of drug in the targeted tissue how much chemotherapeutic drug is in need. Without a doubt, systemic administration has devastating effects on other organs in the case of bone cancer [38]. On the other hand, localized controlled release can provide desired drug concentration in the targeted tissue and also it is able to enhance drug bioavailability $[39,40]$. The amounts of drug loading and release rate are completely dependent on the design of scaffold (Figure 3). In recent years, some inorganic scaffolds with effective controlled release capabilities are designed and cisplatin (cisdichlorodiammineplatinum(II) and doxorubicin as model drugs are used. Although this method showed promising potential to extirpate the remained cancerous cells, these cells can become resistant to this treatment in some cases and consequently fail the whole process [41,42].

\section{Conclusion}

To deal with a bone tumor, surgery is the first approach coming into mind followed by radiotherapy and chemotherapy, but none of which is able to eradicate the cancerous cells remained into the defects wall. Newer therapies, which are added to bone scaffolds, have made the scaffolds multifunctional being responsive to the bone cancer-related issues concurrently with regeneration. The multifunctional scaffolds indicated a promising potential to be replaced with the traditional ones. Certainly, shortcomings are still around the multifunctional scaffolds and further investigations are required to afford a safe clinical approach.

\section{References}

1. A Bigham, S Kermani, A Saudi, A Aghajanian, M Rafienia (2020) On the bioactivity and mechanical properties of gehlenite nanobioceramic: A comparative study. J Med Signals Sensors 10(2): 105-112.

2. S Shkarina, R Shkarin, V Weinhardt, E Melnik, G Vacun, et al. (2018) 3D biodegradable scaffolds of polycaprolactone with silicate-containing hydroxyapatite microparticles for bone tissue engineering: highresolution tomography and in vitro study. Sci Rep 8: 8907.

3. I Izquierdo Barba (2014) Scaffold Designing. Bio-Ceramics with Clin Appl pp. 291-313.

4. F Khosravi, S Nouri Khorasani, E Rezvani Ghomi, MK Kichi, H Zilouei, et al. (2019) A bilayer GO/nanofibrous biocomposite coating to enhance 316L stainless steel corrosion performance. Mater Res Express 6(8): 86470.

5. H Luo, J Xiao, M Peng, Q Zhang, Z Yang, et al. (2020) One-pot synthesis of copper-doped mesoporous bioglass towards multifunctional 3D nanofibrous scaffolds for bone regeneration. J Non Cryst Solids 532: 119856.
6. M Cicuéndez, JC Doadrio, A Hernández, MT Portolés, I Izquierdo Barba, et al. (2018) Multifunctional pH sensitive 3D scaffolds for treatment and prevention of bone infection. Acta Biomater 65: 450-461.

7. V Martin, IA Ribeiro, MM Alves, L Gonçalves, RA Claudio, et al. (2019) Engineering a multifunctional 3D-printed PLA-collagen-minocyclinenanoHydroxyapatite scaffold with combined antimicrobial and osteogenic effects for bone regeneration. Mater Sci Eng C 101: 15-26.

8. F Khosravi, S Nouri Khorasani, S Khalili, R Esmaeely Neisiany, E Rezvani Ghomi, et al. (2020) Development of a Highly Proliferated Bilayer Coating on 316L Stainless Steel Implants. Polym 12(5).

9. M Vallet Regí, E Ruiz Hernández (2011) Bioceramics: From Bone Regeneration to Cancer Nanomedicine. Adv Mater 23(44): 5177-5218.

10. RJ Orentas, B Johnson, J Hodge (2008) Cancer Vaccines: Progress and Promise. Cancer Vaccines Tumor Immun. p. 1-11.

11. JW Lu, F Yang, QF Ke, XT Xie, YP Guo (2018) Magnetic nanoparticles modified-porous scaffolds for bone regeneration and photothermal therapy against tumors. Nanomedicine Nanotechnology Biol Med 14(3): 811-822.

12. Y Liu, R Lin, L Ma, H Zhuang, C Feng, et al. (2020) Mesoporous bioactive glass for synergistic therapy of tumor and regeneration of bone tissue. Appl Mater Today 19: 100578.

13.V Mouriño, AR Boccaccini (2010) Bone tissue engineering therapeutics: controlled drug delivery in three-dimensional scaffolds. J R Soc Interface 7: 209-227.

14. A Bigham, SA Hassanzadeh Tabrizi, A Khamsehashari, A Chami (2018) Surfactant-assisted sol-gel synthesis and characterization of hierarchical nanoporous merwinite with controllable drug release. J Sol Gel Sci Technol 87: 618-625

15. RK Fuchs, WR Thompson, SJ Warden (2019) 2 - Bone biology, In: KM Pawelec, JABT-BRB (Second E Planell (Eds.).), Woodhead Publ Ser Biomater, Woodhead Publishing. pp. 15-52.

16. M Vallet Regi, A Salinas, A Baeza, M Manzano (2018) Smart nanomaterials and nanostructures for diagnostic and therapy. Chem Eng J 340: 1.

17. C Wu, W Fan, Y Zhu, M Gelinsky, J Chang, et al. (2011) Multifunctional magnetic mesoporous bioactive glass scaffolds with a hierarchical pore structure. Acta Biomater 7: 3563-3572.

18. H Wang, X Zeng, L Pang, H Wang, B Lin, et al. (2020) Integrative treatment of anti-tumor/bone repair by combination of MoS2 nanosheets with 3D printed bioactive borosilicate glass scaffolds. Chem Eng J 396: 125081.

19. KM Pawelec (2019) 1 - Introduction to the challenges of bone repair. In: KM Pawelec, JABT-BRB (Second E Planell (Eds.)., Woodhead Publ Ser Biomater, Woodhead Publishing. pp. 1-13.

20. A Baeza (2014) Ceramic Nanoparticles for Cancer Treatment. BioCeramics with Clin Appl. pp. 421-455.

21. A Bigham, F Foroughi, M Motamedi, M Rafienia (2018) Multifunctional nanoporous magnetic zinc silicate- $\mathrm{ZnFe}_{2} \mathrm{O}_{4}$ core-shell composite for bone tissue engineering applications. Ceram Int 44.

22. A Hajinasab, S Saber Samandari, S Ahmadi, K Alamara (2018) Preparation and characterization of a biocompatible magnetic scaffold for biomedical engineering. Mater Chem Phys 204: 378-387.

23. N Bock, A Riminucci, C Dionigi, A Russo, A Tampieri, et al. (2010) A novel route in bone tissue engineering: Magnetic biomimetic scaffolds. Acta Biomater 6: 786-796.

24. C Shuai, Y Cheng, W Yang, P Feng, Y Yang, et al. (2020) Magnetically actuated bone scaffold: Microstructure, cell response and osteogenesis. Compos Part B Eng 192: 107986.

25. A Bigham, AH Aghajanian, S Allahdaneh, SA Hassanzadeh Tabrizi (2019) Multifunctional mesoporous magnetic $\mathrm{Mg}_{2} \mathrm{SiO}_{4}-\mathrm{CuFe}_{2} \mathrm{O}_{4}$ core-shell nanocomposite for simultaneous bone cancer therapy and regeneration. Ceram Int 45: 19481-19488. 
26. M Ansari, A Bigham, HA Ahangar (2019) Super-paramagnetic nanostructured CuZnMg mixed spinel ferrite for bone tissue regeneration. Mater Sci Eng C 105: 110084.

27. M Rafienia, A Bigham, SA Hassanzadeh Tabrizi (2018) Solvotherma synthesis of magnetic spinel ferrites. J Med Signals Sens 8(2): 108-118.

28. Y Iqbal, H Bae, I Rhee, S Hong (2016) Control of the saturation temperature in magnetic heating by using polyethylene-glycol-coated rod-shaped nickel-ferrite $\left(\mathrm{NiFe}_{2} \mathrm{O}_{4}\right)$ nanoparticles. J Korean Phys Soc 68 587-592.

29. A Bigham, AH Aghajanian, S Behzadzadeh, Z Sokhani, S Shojaei, et al (2019) Nanostructured magnetic $\mathrm{Mg}_{2} \mathrm{SiO}_{4}-\mathrm{CoFe}_{2} \mathrm{O}_{4}$ composite scaffold with multiple capabilities for bone tissue regeneration. Mater Sci Eng C 99: 83-95.

30. H Ma, C Jiang, D Zhai, Y Luo, Y Chen, et al. (2016) A Bifunctional Biomaterial with Photothermal Effect for Tumor Therapy and Bone Regeneration. Adv Funct Mater 26: 1197-1208.

31. W Dang, B Ma, Z Huan, R Lin, X Wang, et al. (2019) LaB ${ }_{6}$ surface chemistryreinforced scaffolds for treating bone tumors and bone defects. Appl Mater Today 16: 42-55.

32. S Fu, H Hu, J Chen, Y Zhu, S Zhao (2020) Silicone resin derived larnite/C scaffolds via 3D printing for potential tumor therapy and bone regeneration. Chem Eng J 382: 122928.

33. W Dang, T Li, B Li, H Ma, D Zhai, et al. (2018) A bifunctional scaffold with $\mathrm{CuFeSe}_{2}$ nanocrystals for tumor therapy and bone reconstruction. Biomaterials 160: 92-106.

34. H Ma, C Feng, J Chang, C Wu (2018) 3D-printed bioceramic scaffolds: From bone tissue engineering to tumor therapy. Acta Biomater 79: $37-$ 59.

ISSN: 2574-1241

DOI: 10.26717/BJSTR.2020.27.004572

Hongrong Luo, Seeram Ramakrishna. Biomed J Sci \& Tech Res

(C) This work is licensed under Creative

Submission Link: https://biomedres.us/submit-manuscript.php
35. RR Castillo, M Colilla, M Vallet Regí (2017) Advances in mesoporous silica-based nanocarriers for co-delivery and combination therapy against cancer. Expert Opin Drug Deliv 14: 229-243.

36. A Bari, N Bloise, S Fiorilli, G Novajra, M Vallet Regí, et al. (2017) Coppercontaining mesoporous bioactive glass nanoparticles as multifunctional agent for bone regeneration. Acta Biomater 55: 493-504.

37. A Baeza, D Ruiz Molina, M Vallet Regí (2017) Recent advances in porous nanoparticles for drug delivery in antitumoral applications: inorganic nanoparticles and nanoscale metal-organic frameworks. Expert Opin Drug Deliv 14: 783-796

38. M Manzano (2014) Ceramics for Drug Delivery. Bio-Ceramics with Clin Appl. pp. 343-382.

39. A Bigham, AH Aghajanian, A Saudi, M Rafienia (2020) Hierarchical porous $\mathrm{Mg} 2 \mathrm{SiO} 4-\mathrm{CoFe} 2 \mathrm{O} 4$ nanomagnetic scaffold for bone cancer therapy and regeneration: Surface modification and in vitro studies. Mater Sci Eng C 109: 110579.

40. JL Paris, M Manzano, MV Cabañas, M Vallet Regí (2018) Mesoporous silica nanoparticles engineered for ultrasound-induced uptake by cancer cells. Nanoscale 10: 6402-6408.

41. A Farzin, M Fathi, R Emadi (2017) Multifunctional magnetic nanostructured hardystonite scaffold for hyperthermia, drug delivery and tissue engineering applications. Mater Sci Eng C 70: 21-31.

42. S Mondal, U Pal (2019) 3D hydroxyapatite scaffold for bone regeneration and local drug delivery applications. J Drug Deliv Sci Technol 53: 101131.

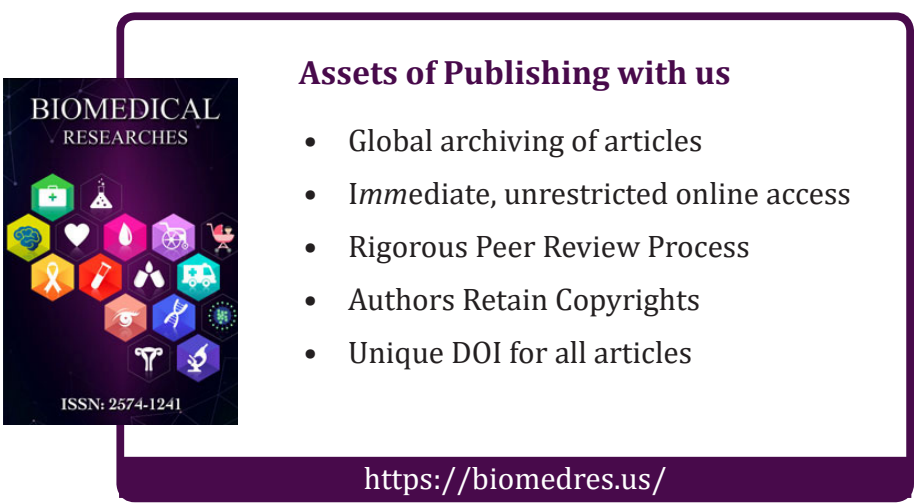

